\title{
Tidal and Wind-Driven CuRRENTS FROM OSCR
}

\author{
By David Prandle
}

$\mathrm{T}$

WO IMPORTANT ASPECTS of tidal currents are (1) their temporal coherence and (2) their constancy (over centuries). The first rigorous evaluation of an Ocean Surface Current Radar (OSCR) system exploited these characteristics using sequential deployments of the one available unit with subsequent combination of radial components to construct tidal ellipses (Prandle and Ryder 1985).

\section{Specifications for Tidal Mapping}

The Rayleigh criterion for separation of closely spaced constituents in tidal analysis suggests observational periods exceeding the related beat frequency, this dictates $15 \mathrm{~d}$ of observations to separate the two largest constituents $M_{2}$ and $S_{2}$. For tidal elevations this criterion is often relaxed; however, while elevations show a noise:tidal signal ratio of $0(0.1-0.2)$, the same ratio for currents is $0(0.5)$. Moreover, wind and wave current components are generally largest at the surface, and hence for OSCR observations the ratio may be even higher. Consequently $30-\mathrm{d}$ observational periods are recommended. Prandle et al. (1993) show that. from analyses of a sequence of data sets of this length, 7 constituents could be determined with standard deviations of $\sim 0.1$ of amplitude for $\mathrm{M}_{2}, \mathrm{~S}_{2}$, and $\mathrm{N}_{2}$ and 0.2 for $\mathrm{O}_{1}, \mathrm{~K}_{1}, \mathrm{M}_{4}$. and $\mathrm{MS}_{4}$. An associated problem arises with selecting specified relationships for closely spaced constituents not explicitly determined; using adjacent elevation data may be suspect. A further difficulty arises in shallow water in comparing OSCR results with values from either moored instruments or models based on different vertical reference frames. Lane et al., (in press) indicate some possible solutions to this problem.

Figure 1 (Prandle 1991) shows typically close agreement between tidal ellipse distributions derived by combining OSCR measurements from a total of 10 sites with values from a fine grid numerical model. The extent of this agreement can

David Prandle, Proudman Oceanographic Laboratory. Bidston Observatory. Birkenhead L43 7RA. UK. be seen by comparing calculations of $\mathrm{M}_{2}$ tidal vorticity distributions $\langle\partial V / \partial X-\partial U / \partial Y\rangle$ from OSCR measurements with corresponding model calculations (Prandle 1987).

\section{Tidal Residuals}

The propagation of tidal energy from the ocean into shelf seas produces an attendant net residual current $\mathrm{U}_{\circ}$ of $0.5(\hat{\mathrm{U}} \xi / \mathrm{D}) \cos \theta$ ( $\hat{\mathrm{U}}$, oscillating current amplitude; $\xi$, elevation amplitude; $D$, water depth: $\theta$, phase difference between $\hat{U}$ and $\xi$ ). In U.K. waters $U_{0}$ is typically $0-3 \mathrm{~cm} \mathrm{~s}^{-1}$ compared with $\hat{U}$ of $40-100 \mathrm{~cm} \mathrm{~s}^{-1}$, thus conventional current meters often fail to resolve $U_{v}$. Moreover, numerical models that accurately simulate $\mathrm{M}_{2}$ may not resolve $U_{0}$ with the same accuracy. Year-long deployments of OSCR, in the Dover Straits (Prandle et al., 1993) and the North Channel of the Irish Sea (Howarth et al., 1995), enabled, for the first time, these net tidal residual currents to be accurately resolved by direct measurement. But. as so often occurs in science, enhanced resolution of the instrumentation reveals finer scale dynamical processes. Figure 2 shows a residual surface current gyre differentiated from these long-term measurements in the Dover Strait. Such gyres are not exceptional but rather a characteristic of most coastlines, although rarely identified with conventional instrument or airborne sensors.

\section{Wind-Driven Currents}

\section{Nontidal Currents}

Removal of the tidal component from High Frequency (HF) Radar current observations leaves residuals that may include contributions from: direct (localized) wind forcing, indirect (larger scale) wind forcing, surface waves, and horizontal and vertical density gradients. Interaction of any of these components with the tidal component can generate significant modulation of the latter contributing an additional nontidal residual. Selective filtering of the nontidal currents into frequency bands can be used to separate many of these components.
.. enhanced reso-

Iution of the instru-

mentation reveals

finer scale dynamical

processes. 


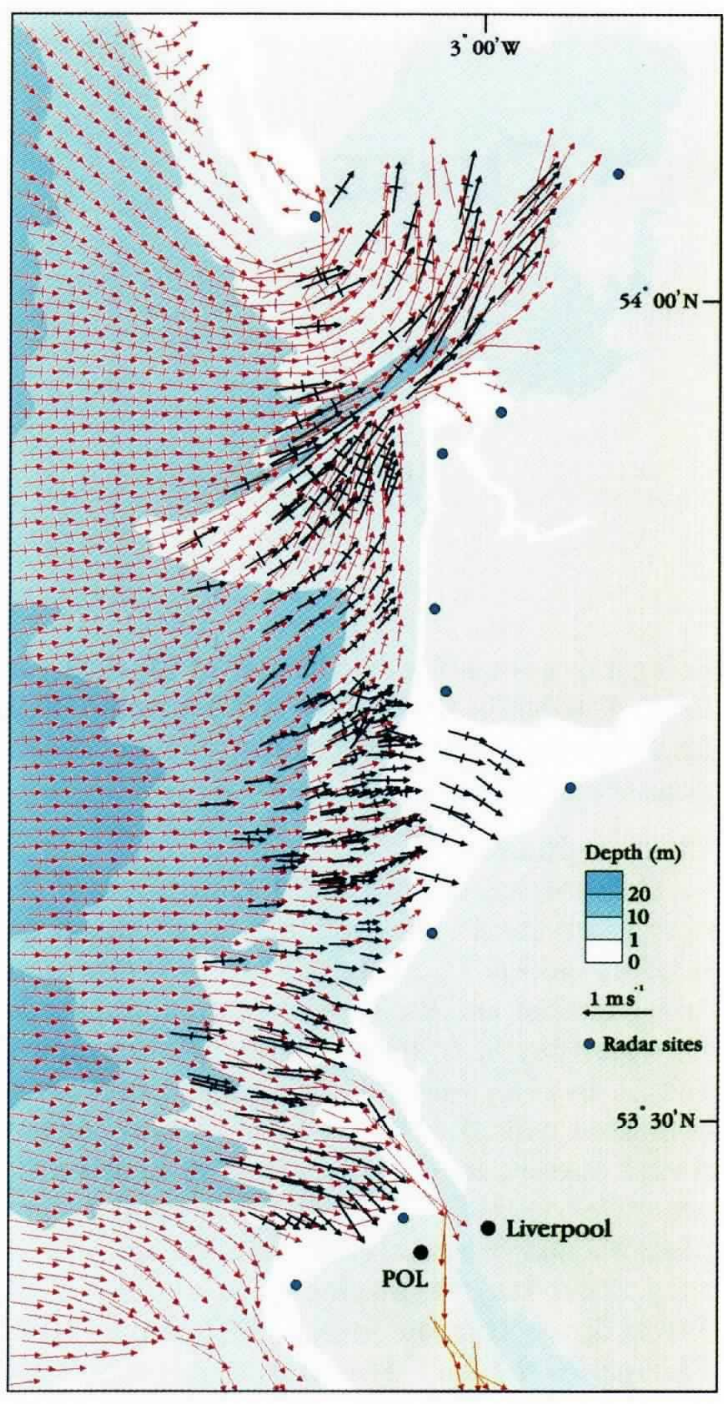

Fig. 1: $M_{2}$ tidal ellipses, OSCR (black) versus model.

Persistent residual surface currents of typically $10-20 \mathrm{~cm} \mathrm{~s}^{-1}$ are regularly observed with deployments of the OSCR system around the U.K. coast. These can often be dynamically related to horizontal density gradients (Prandle and Matthews 1990). Likewise jet-like currents of up to $14 \mathrm{~cm} \mathrm{~s}^{-1}$ have been observed linked with frontal dynamics (Matthews et al., 1993). Souza and Simpson (1996) show how vertical density gradients modulate surface tidal currents.

In deep water the oscillatory orbital velocities of surface waves do not show any obvious aliasing on the Bragg peaks, but in shallow water any associated net drift component may influence "current" measurements.

\section{Wind-Forced Currents}

Relating observed wind-driven currents to wind forcing is notoriously difficult. Both the wind itself and the associated currents exhibit appreciable fine-scale (temporal and spatial)

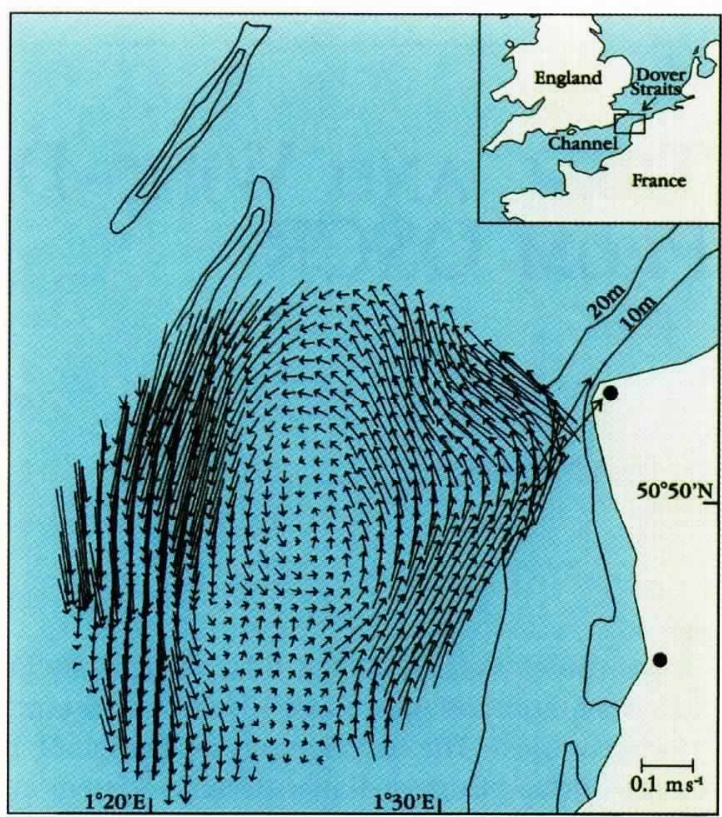

Fig. 2: Residual (30 d mean) gyre from OSCR Mk II.

variability. In shallower water, wind forcing may be partially balanced by surface slopes. In straits these slopes can subsequently generate currents orders of magnitude greater than indicated by localized forcing (Prandle 1993). However, statistically significant relationships between wind and residual surface currents have been derived from all OSCR deployments. Both the steadystate Ekman spiral response and rotating inertial currents have been identified (Fig. 3). The steady-state response is typically 1 or $2 \%$ of wind speed, increasing in magnitude in deep water and veering increasingly toward the theoretical deep water values of $45^{\circ}$ to the right of the wind.

\section{Determining Current Profiles From Surface Currents}

Construction of tidal current profiles from surface values can be completed, qualitatively, using simple theory that requires the specification of a vertical eddy viscosity coefficient, $\mathrm{E}$, and a bottom friction coefficient $\mathrm{k}$ (Prandle 1982). Estimates of both $\mathrm{E}$ and $\mathrm{k}$ may be made from the variation in wind-forced response in water of varying depths. Vertical profiles of the wind-forced component in open seas can similarly be calculated from Ekman spiral theory.

By substitution of observed surface currents into the horizontal momentum equation, localized surface gradients can be constructed. By integrating these gradients over the region of radar coverage, both an $\mathrm{M}_{2}$ co-tidal chart (using a reference value) and a mean sea level distribution were calculated for the Dover Strait (Prandle et al., 1993). 

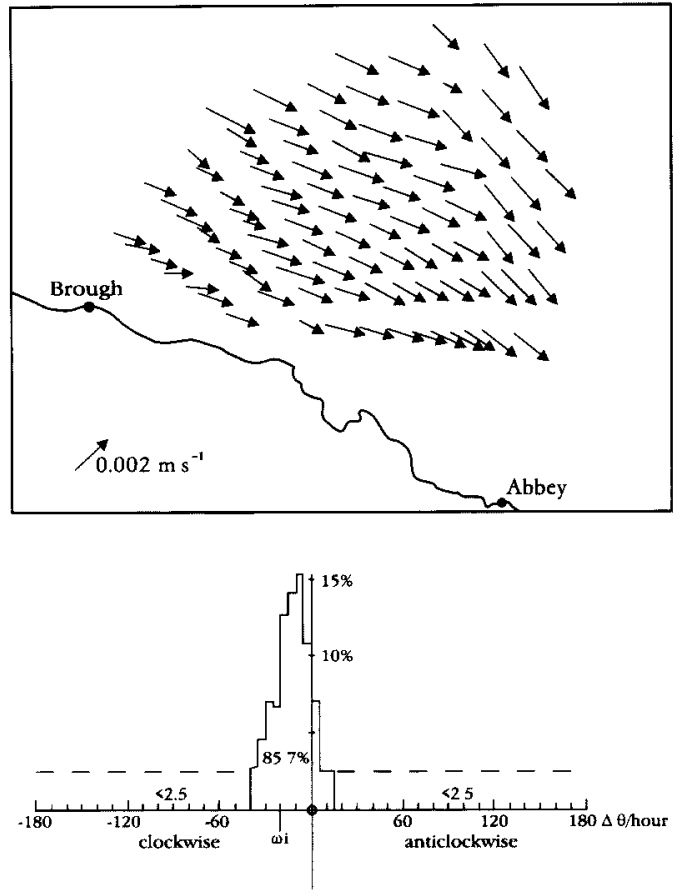

Fig. 3: Wind-forced currents (shown for $1 \mathrm{~m} \mathrm{~s}^{-1}$ $W$; top panel). Histogram of rotation rate of residual currents (bottom panel).

\section{Future Applications}

The OSCR results described here have been restricted to the $26-\mathrm{MHz}$ system, the potential of the finer scale resolution afforded by operation at $50 \mathrm{MHz}$ is demonstrated elsewhere. The potential for longer range HF Radar current measurements has yet to be fully exploited. Use of HF Radar for permanent monitoring of strategic straits, such as for the North Channel and Dover Strait described here, could form part of the Global Ocean Observing System to detect net trends in oceanic circulation. With the performance of HF Radar now widely established, the greatest obstacle to wider use is capital cost: however. HF Radar systems are not vulnerable to loss and damage inherent with oceanographic instrumentation.

The range of synergistic modes of linking HF Radar surface current measurements with in situ and shipborne Acoustic Doppler Current Profiler (ADCP) (Matthews et al., 1993), remote sensing, numerical modeling, etc., has yet to be fully developed. Perhaps the greatest potential of such synergy is in real-time operational deployments. Examples include use of HF Radar for navigation into major ports, management of coastal discharges/withdrawal, tracking of accidental spillages, assimilation (updating) of storm surge prediction models, etc.

In principle, horizontal dispersion coefficients can be determined from the spatial variability in velocities observed by HF Radar. In practice, such estimates depend on the spatial resolution, sampling period, and instrumental errors of the system. Experiments to explore such sensitivities involving concurrent dye dispersion and drogue tracking would be useful.

An exciting prospect is to link such extended applications to related development in the radar technology. Thus, for example, a "Grand Challenge" for coastal researchers is to predict coastal bathymetric evolution, involving long-term continuous measurement of currents, waves, winds, and bathymetry. An HF Radar system operating at variable frequency (simultaneous or consecutively) might be optimally tuned for determining each of these parameters.

\section{References}

Howarth, M.J., A.J. Harrison, P.J. Knight and R.J. Player, 1995: Measurement of net flow through a Channel. In: Proceedings of the IEEE Fifth Working Conference on Current Measurement. IEEE. St. Petersburg. Florida, February 7-9, 121-126.

Lane, A.. D. Prandle, A.J. Harrison, P.D. Jones and C.J. Jarvis. Measuring fluxes in tidal estuaries: sensitivity to instrumentation and associated data analyses. Estuarine, Coastal Shelf Sci. In press.

Matthews, J.P., A.D. Fox and D. Prandle, 1993: Radar observation of an along-front jet and transverse flow convergence associated with a North Sea front. Cont. Shelf Res., 13, 109-130.

Prandle, D., 1982: The vertical structure of tidal currents and other oscillatory flows. Cont. Shelf Res., I, 191-207. 1987: The fine-structure of nearshore tidal and residual circulations revealed by $\mathrm{HF}$ radar surface current measurements. J. Phys. Oceanogr., 17, 231-245.

1991: A new view of near-shore dynamics based on observations from HF radar. Progr. Oceanogr., 27, 403-438. 1993: Year long measurements of flow through the Dover Strait by H.F. Radar and Acoustic Doppler Current Profilers (ADCP). Oceanologica Acta, 16, No. 5-6. 457-468

and K.D. Ryder, 1985: Measurement of surface currents in Liverpool Bay by high-frequency radar. Nature. $315,128-131$.

and J. Matthews, 1990: The dynamics of nearshore surface currents generated by tides, wind and horizontal density gradients. Cont. Shelf Res., 10, 665-681. S.G. Loch and R. Player, 1993: Tidal flow through the Straits of Dover. J. Phys. Oceanogr., 23, 23-27.

Souza, A.J. and J.H. Simpson, 1996: The modification of tidal ellipses by stratification in the Rhine ROFI. Cont. Shelf Res., 16, 997-1008.
P erhaps the greatest potential of such synergy is in realtime operational deployments. 